Session 1531

\title{
Balancing Rigor and Rapport in the Engineering Classroom: Where Should the Line Be Drawn by New Engineering Educators?
}

\author{
Robert D. Engelken, Ph.D., P.E. \\ Director of Electrical, Computer, and Information Engineering \\ Professor of Electrical Engineering \\ Arkansas State University \\ P.O. Box 1740 \\ State University (Jonesboro), AR 72467 \\ bdengens@astate.edu
}

\section{Introduction and Background}

New engineering educator(s) (NEE) enter academia with idealizations of being exemplary instructors and advisors [1-8], even rising above weaknesses of their own professors. They start with a set of "when I become a professor, I'm going to/not going to ..." ideas formulated in the trenches of student-hood. They are confident that they can achieve both popularity and rapport with students, and excellence in teaching, advising, and other student relations. However, unless already well seasoned as graduate assistants in dealing with students, they are usually disillusioned as realities of undergraduate education sink in, for example, (1) some students don't care about learning, (2) some students can be less than honest if expedient, and (3) many students play the system for maximum results with minimum effort, time, and money. NEE will eventually see that human nature, not noble idealism, dominates student attitudes and behaviors, as in all lives and relationships, and that not every Johnny or Jane fits his/her idealization and personal history of a knowledgehungry, hard working, and ethical college student.

Historically, standards and rules in colleges and universities were stringent and unforgiving. Higher education was not the entitlement of all young people, as is now the norm, and competition for admission and survival in college was fierce. Professors had almost absolute power regarding attendance, structure, content, assessment, and grades and anything less than near-perfection in student performance or behavior often led to summary expulsion or disciplinary measures. Fun, self-esteem, social consciousness, relationships, learning styles, and even marketability and fairness were irrelevant in rigorous studies of the classics, foreign languages, mathematics, science, philosophy, religion, and the arts. Underwater basket weaving and group study- type courses were nonexistent. Although from today's perspective such a modus operandi seems harsh and insensitive, it did provide, for those that survived, a firm foundation in knowledge and solidification of diligence, perseverance, creativity, and morality. One could be certain that a college 
graduate with a specific major and passing grade point average possessed specific knowledge and skills, and had been through the rigor and example provided by the college experience.

Fast forward to 2003 in which this may not be true in some instances. Modern education theory, political correctness, financial pressures, and other influences have made the modus operandi much more flexible and student friendly. Although not entirely bad, something was lost in the translation regarding standards, rigor, and consistency. This was not as extreme in engineering as in some other disciplines, thanks to the rigorous, objective, and competitive nature of the profession, and ABET accreditation standards. However, one can still argue that such influences have negatively impacted engineering education. College students still need a solid foundation in knowledge and skills related to their major and a broader set of disciplines generally attributed to a well-educated individual. They also still need character development and acceleration of maturation. They also need to have the marketable knowledge, skills, and attributes needed to enjoy a fulfilling and reasonably lucrative career.

Many students come to college with two strikes against them. Mediocre high school educations, unstable family situations, a childhood of prosperity, diversions, and pleasure as well as little responsibility and deference to authority, and too many sideline commitments such as girlfriends/boyfriends and part-time jobs (to pay for their expensive automobiles and insurance) all increase the challenge of succeeding in college. Professors are aware of the needs for rigor and excellence in the classroom and sensitivity to the above factors that compromise such. Experienced faculty have already come to equilibrium in balancing standards versus sensitivity, and rigor versus rapport. However, NEE often have difficulty in establishing equilibrium and may start their teaching career as either too easy and casual, or too hard and hard-line. Some will go through a series of under damped oscillations (flip-flops) between these extremes before reaching equilibrium. Professors are in a double bind or Catch 22 in that their job fundamentally involves defining high standards of performance and demeanor that, when enforced, have potential to eliminate the very reason for their job, namely students. It's analogous to a statement attributed to General Robert E. Lee (paraphrased): To be a good general requires that one must be willing to throw at the enemy (ignorance and immaturity) and sacrifice (via high standards and resultant drops, transfers, withdraws, and bad grades), with no holding back, that which he loves the most, namely his soldiers (students).

\section{Common NEE Teaching Scenarios}

Experienced NEE will design initial style, policies, and standards close to what they eventually settle to after several years. Some NEE do not have to go through significant modifications but only minor refinements. However, others may have trouble in initially targeting optimum balance between hard and easy, and strict and accommodating. Due to 
influences discussed in the previous section, such NEE may err in initial approach and will have to, through feedback, learn to modify methodology over time. It would be nice if NEE could make and assess incremental adjustments over time and approach an eventual optimum equilibrium in a manner akin to critical damping or over damping. Unfortunately, when things don't work and criticisms accrue, some NEE make sudden dramatic changes, namely a flip flop or series of flip-flops attenuating toward optimum style. The initial state can be too easy and accommodating or too hard and hard-line. In either case, problems accumulate and provide escalating feedback that things aren't at their best.

Although standards, class policies, and instructor's personality and style with students generally track, this is not always the case. A few NEE can be easy-going and personable but still have high standards and teach a meaty class. Similarly, even fewer NEE can be undemanding in student performance but sticklers for a tight ship in class atmosphere and policies. There are four basic styles: (1) easy and undemanding in teaching, work required, and grading standards and lax, casual, and accommodating regarding policies and interaction with students, (2) difficult and demanding in academics and strict regarding policies and student demeanor, (3) easy regarding academics but hard-line regarding policies and demeanor, and (4) difficult regarding academics but personable and reasonable with students. NEE could also be on-target regarding either academics or policy and either too hard or easy regarding the other. (1) and (2) are the most common. Of the four, (4) would be the least objectionable.

These are analogous to four types of authority structure between parents and children: (1) permissive and loving/communicative, (2) strict and unloving/ uncommunicative, (3) permissive and unloving/uncommunicative, and (4) strict and loving/communicative. Style (4) generally leads to the most prepared, accomplished, well-adjusted, responsible, happy, and secure children and subsequent adults, with (2) and (3) in a tie in producing the least well-adjusted youngsters.

Being easy and/or casual may be popular with students but leads to problems. Students are perceptive regarding boundaries of what they can get by with and will test NEE by crossing them. If professors do not unambiguously define and, when tested, enforce reasonable standards and policies, students will take increasing liberties in behavior, for example, attendance, punctuality, talking, eating, drinking, appearance, dress, respect for the professor, etc. Liberties will also be taken regarding submission, neatness, and quality of submitted work, note taking, and time spent studying. Students may not stay up-to-date on course material and better students may feel cheated out of being taught what they need. Poorer students may like this approach but think that they are doing well in a solid class when they are also being cheated.

More insidious is reduction in respect for and obedience to NEE trying to be easy, likeable, and accommodating. Such instructors may become thought of as a joke or 
pushover. Students learn to try to negotiate scores, grades, submission dates, and number and difficulty of assignments. Every time that an instructor doesn't stand his/her ground, particularly if it appears that he/she has been manipulated, students will become even bolder. Things can spiral out of control quickly.

A young NEE can be a target of trouble-making students who deliberately try to disrupt class. Common in high schools, such students must be dealt with conclusively. A related issue involves demands for instructor help and time by students. Again if the NEE doesn't define what's appropriate, students may request that he/she waste class time answering trivial or redundant questions, working excessive numbers of homework problems, or reviewing for tests. Some may also camp out in the instructor's office during office hours with the same requests.

Faculty colleagues discern such problems through the grapevine or from observation and may or may not offer counsel, depending upon personal familiarity with and opinion of the NEE. If there is any perception of brashness, unconventionality, one-upmanship, or "I' $m$ going to change the academic world" on the part of the NEE, colleagues may give him/her enough rope to hang and blow in the wind.

They (and students) will make sure that administrators hear about the NEE's deviations from the norm and problems. Depending upon departmental and institutional philosophy and policies, two things can happen. If a formal assessment procedure for pre-tenure faculty exists, NEE may obtain prompt constructive criticism at that time. Student/course evaluations and annual reviews by chairs also provide opportunities for adjustments. The first year's or two's merit raises can also pass a message. Conscientious mentors, directors, chairs, and even deans will proactively approach the offending NEE promptly upon hearing of problems.

When formal NEE assessment is minimal or academic freedom is considered highly important, feedback may be less prompt. Colleagues and superiors may feel that the NEE has the prerogative to chart his/her own course and will eventually work things out. Some chairs and deans may inwardly be pleased with easy, loose, and popular styles of NEE in the name of recruitment, retention, credit hours, tuition, and happy students. On the other hand, colleagues are apt to view the young upstart's popularity with envy, contempt, and "He'll learn" and/or "We'll show him".

One would think that such a NEE would quickly perceive such problems. However, it's a fact that one is often the last to perceive one's own faults and problems, especially if convinced that his/her underlying principles and philosophies are valid and that things will eventually work out. Such NEE may feel strongly they can be effective teachers by being easy, loose, and popular, that students will be sufficiently conscientious to do the right things (studying, learning, behavior, etc.) without coercion, and that problems with this style are simply transient anomalies. Such NEE may let problems and criticisms pile up to 
critical mass at which point an explosive flip-flop in style may occur. A wiser, perceptive NEE will discern developing problems and make incremental adjustments in style earlyon.

The other extreme is an initial style too demanding and inflexible, that is, a drill sergeant approach akin to the way professors often ran classes decades ago. Many NEE fresh out of the advanced and demanding rigor of graduate school are fired-up to teach high-level course material, and may have forgotten that they weren't knowledgeable and acclimated to difficult, hard work as undergraduates. They may forget that undergraduates have commitments that preclude the nearly $100 \%$ dedication required in graduate school, for instance, close ties to family, part-time jobs, boyfriends/girlfriends, hobbies, and fraternities/sororities. Undergraduate engineering majors usually take 16-18 credit hour (5-6 classes) versus the 1-2 classes taken per semester by a typical graduate student and are already stretched to the limit just grinding out all of the homework required in these multiple classes.

Sometimes NEE desire to avoid the partially hand-waving manner in which some of their undergraduate courses were taught by utilizing a logically more elegant but mathematically more difficult framework, for example, three dimensional vector calculus, transform, or matrix approaches to one dimensional differential equations. Such approaches leave students behind and raise eyebrows. Some NEE also teach as if all students are graduate school-bound and lose track that some may end up doing machine repair and quality control at the ACME Widget Manufacturing Company in Podunkville.

Another motivation for a NEE being challenging and stringent is a misguided desire to show faculty colleagues how knowledgeable, advanced, and professional he/she is. The NEE wants to appear totally in control of classes and fully capable of teaching the material.

Some NEE may start out strict in standards, policies, and style because of bad experiences with students while a graduate teaching-assistant. If the NEE was burned as a TA, they may have decided to nip these problems in the bud in their new academic career. There is a strong grain of truth in this mindset but a common sense, balanced approach is much better than the boot camp approach.

A handful of individuals who may be harsh due to personality problems, for example, neurotic desire to control, judge, and pass sentence on others or a phobia about appearing weak or incompetent. Some may have unresolved problems from childhood and some may be really insecure. Although uncommon, such individuals will have more difficulty in converging to a middle-of-the-road classroom methodology than those who were simply off-target in initial style. Now, many influences motivating high standards and tight classroom environment are justified, for example, satisfying ABET criteria and a desire to produce the best trained and marketable graduate possible. NEE should understand that what makes students happy now may not make them happy when they get on the job and 
discover that their education was inadequate for them to compete. Thus, reasonably high standards of performance and demeanor are justified. It all boils down to common sense, pragmatism, and balance [2].

Students will react to harsh instructors with resentment, dislike, fear, and heel- dragging (civil disobedience). They will scoff at him/her in private. If demands or difficulty regarding reading, assignments, and tests are excessive, all but the best students may not be able to keep up and either drop the course or decide to settle for a $\mathrm{C}$ or $\mathrm{D}$ with minimal effort. The most talented students may be able to scramble and rise to the occasion with hard work but will still resent the excessive demands.

Students in such courses complain to other students, professors, and administrators faster and more zealously than students in courses too easy or casual. They may unite and approach chairs and deans as a group or with a petition. This will generally lead to immediate discussions between the NEE, chair or dean, and sometimes even students and the NEE will be strongly counseled to make adjustments if the complaints are valid.

For less extreme cases, data such as high drop rates, low enrollments, low average final grades, and accumulating complaints will reach a point where chairs, deans, or senior faculty can no longer chalk it up to the NEE's inexperience or excuse it in light of academic freedom, but will be compelled to do something. Formal assessments of and conferences with NEE by superiors can catch such problems early. Without these, things may have to reach a boiling point for change to occur. If things have really gotten out of hand, chairs or deans may mandate immediate specific changes. NEE may on their own decide to make dramatic changes, even to the point of flip-flopping to the opposite extreme, to quickly repair potential damage in reputation, likelihood of promotion and tenure, merit raises, and other perks and power. The extent of the changes will depend upon the severity and number of complaints, whether chairs or deans have intervened, and the maturity, confidence, experience, and stability of the NEE.

Even with such oscillation, the NEE will have been sensitized to the need to improve and to the scrutiny of others. He/she will now fear losing their job or not being tenured, will be attentive to the consequences of these changes, and use this feedback for ongoing improvement, as is the goal of the new ABET 2000 accreditation criteria. Thus, the settling time associated with subsequent iterations will be short. The NEE will now quickly detect problems in going too far the other way from an optimum norm and will make a prompt second round of modifications in standards, policies, and style.

There will be some steady state error between the standards, policies, and style to which a professor eventually converges (his equilibrium or steady state) and the ideal set point defined by him, students, superiors, or ABET. Many circumstances and constraints must be simultaneously considered, for example, class size and average student intelligence, budget (particularly relevant to laboratory courses), textbook, etc. There will always be 
differences of opinion with colleagues, superiors, and students regarding what's best. Minor steady state errors will be chalked up to expediency, circumstances, and academic freedom. The real test is how, over time, a NEE's students do in higher-level courses and ultimately in either graduate school and/or an engineering career.

Students will become aware of revised instructor philosophy and notice new approaches. There may be some attitude of "poetic justice" and relief among students and they may again scoff at the professor behind his back. However, this is usually temporary and, over time, students' impressions of and respect for the professor will improve if the new ways of doing things are close to what they should be. Over time, drop rates and complaints will decrease and enrollments, popularity, and respect increase.

However, a certain damage will be permanent. Colleagues and superiors will remember the problems and may bring them up during promotion and tenure deliberations, even years later. The problems and mandated corrections may be documented in the NEE's personnel file and raise their ugly heads relative to future recommendation letters, analysis by new chairs and deans, and even the NEE's attempt to become an administrator decades later. Thus, it behooves the NEE, superiors, and senior colleagues to implement an early warning system of observation, data collection, assessment, and feedback so that problems can be remedied early, preferably within no later than a semester. There needs to be frank definition of what's expected when the NEE is hired and, in addition to formal assessments, frequent informal chats with chairs or mentors regarding the NEE's progress and problems.

\section{Recommended Strategies for New Engineering Educators}

There are strategies that NEE can use to minimize the odds of being off-track in initial classroom methodologies. Some have been implied in the previous discussion. Some are common sense and consistent with human nature and others based upon experience.

A. Anticipate consequences and reactions associated with one's standards, policies, and teaching style. Look down the road with the blinders off and use common sense as to what is likely. Use decision making theory by assigning probabilities and importance to possible consequences of a decision, policy, or action. Examine worst case, best case, and most likely scenarios. Make sure that payoffs of the best and most likely scenarios are worth the risk of the worst case, and that one could withstand results of the worst case if it has reasonable probability.

B. Recall one's experiences as a student and analyze these objectively, not emotionally. Mentally survey one's past professors, pick their best characteristics, and analyze worst characteristics, styles, and policies with the advantage of maturity and hind sight. Assimilate good characteristics and avoid any that were clearly wrong or ineffective. 
Do not subconsciously try to get even with an offending professor years later by rejecting everything that he/she did. This memory of professors will always serve as the baseline of one's approach to academia, just as that of parents and family do to one's approach to life.

C. Apply The Golden Rule ("So in everything, do to others what you would have them do to you..." [14]) and consider how one may have felt about some anticipated action, policy, or standard when he/she was a student. Do a little mental role exchanging/playing with one's students. However, approach this from a long-term perspective. In the short term, many students may be happy with an undemanding, casual course and professor but most will learn in graduate school or in a career that such a course had not cut the mustard. They will value a more challenging and demanding course more in the future, as long as the professor is reasonable and balanced.

D. Be firm, fair, and consistent. This line was a favorite of Mr. W.R. Glenn, the author's Little League baseball coach, $7^{\text {th }}$ grade geography teacher, $9^{\text {th }}$ grade civics teacher, and driver's education instructor at Walnut Ridge, Arkansas High School in the late 1960's and early 1970's. Mr. Glenn was a fine teacher and a human being and practiced this philosophy every day. His example and legacy are still part of the culture of education in Northeast Arkansas years after his retirement and passing away.

Students accept, indeed respect, a firm no-nonsense approach to education if reasonable, fair, consistent, and predictable with no favoritism or inconsistency. Decide on standards and policies carefully but once in place, apply them consistently and fairly, as in the "Red Hot Stove Rule" of management: If one touches a red hot stove (breaks a rule or earns a reward), he/she will always get burned (bear the corresponding penalty or reward) regardless of personality, reason, or circumstances. On the other hand, there are few things that can damage respect for an educator like being inconsistent, unfair, or arbitrary.

E. However, be sufficiently empathetic and flexible to hear a student out and, if a truly unique, emergency, or catastrophic reason exists for a student's offense or poor performance, make a prudent compassionate exception to the penalty. Examples include death or severe illness in the family or among friends, a mandatory court appearance or jury duty, or important, nearly one-of-a-kind opportunities such as an interview trip or important activity of a university-sanctioned organization such as athletics or a student club. Some universities mandate that professors accommodate commuter students missing classes because of weather conditions or sanctioned university athletic competitions. However, some situations will not be covered by institutional policy and the professor will have to serve as judge and jury. Again, apply common sense and the Golden Rule and consider a student's history and reputation for offenses, asking for exceptions such as make-up tests or postponed 
deadlines, and other irregular negotiations with instructors. One might be less accommodating with a known cut-up, sloucher, or trouble maker but cooperative regarding a serious student's first such offense. Require objective documentation similar to the old written excuse in high school rather than just accept a student's word. Even good students are not always above distorting the truth.

F. Aim for balance and "moderation in all things" in one's initial approach to the classroom. Some NEE enter academia with a misguided notion that they're going to change the (academic) world with their insightful, innovative, and extreme methods. Remember that thousands of other engineering professors have already been through the same experiences and the way that they do things may not be a bad target as an initial set point. Incremental improvements can be made over time as the NEE gains concrete experience. Observe how experienced professors approach standards, policy, and style and don't deviate too much from the average of these, the so-called norm for the department or college. If one does, he/she may incur raised eyebrows, gossip, eventual wrist slapping, or worse, for example deliberate reputation smearing and sabotage from colleagues and students.

G. Also, seek out advice from senior colleagues and superiors on a regular, albeit sometimes informal, basis. When newly hired, ask questions about the local department, college, and university infrastructure, policies, resources, chain of command (both formal and informal; that is, the "pecking order"), philosophy, and standard methodologies. Study key documents, for example previous ABET self studies, the faculty handbook, student style manuals, and the college catalog. Become knowledgeable about these to avoid future surprises and problems. Try to arrange formal or informal mentoring by a senior professor. Frequently touch base with the mentor, other faculty, chair, and perhaps dean with questions and for advice and feedback. One of the worst mistakes that a NEE can make is to go it alone, thinking that all is okay and not promptly perceiving and addressing festering problems.

H. Make sure that one covers all topics in the catalog description and/or outline for the course. These have evolved over time with input by senior faculty and are based upon sound wisdom and what's prerequisite for subsequent courses. Do not unilaterally decide to revamp these topics or the manner in which they have normally been taught without agreement of not only chairs but also other relevant faculty. NEE probably need to start out using the same textbook as used the previous time that the course was taught unless specifically invited by senior faculty and/or the chair to choose an alternative.

I. Do not come in and try to immediately revamp the curriculum with new courses or changes in degree plan. This will enrage faculty colleagues. Again, over time, acquire experience and then diplomatically suggest curriculum changes or new courses [9]. To come in like an arrogant, overly confident "bull in the china cabinet" will label one as 
a greenhorn, upstart, flash-in-the-pan, or worse and lead to hard feelings that will last. Remember that recommended changes imply that the status quo designed and fostered by current faculty is inadequate. Recommendations for changes must always be approached very diplomatically.

J. Pay one's dues with respect and deference for senior faculty. Accept that, as the new person, one may have to bite one's tongue, swallow one's pride, and perhaps take on less-than-preferred courses and responsibilities, just as most of the senior faculty had to do when they were a NEE. Be willing to accept and faithfully perform grunt work, particularly teaching time-intensive laboratory courses, freshman-level courses, or outof-department service courses for non-majors. NEE often get stuck with night or weekend public relations or recruiting activities. As one cheerfully performs such tasks with excellence, one's reputation will develop and one will gradually slide into whatever perks and privileges are associated with being a more experienced professor. Colleagues and superiors will "take care" of such a NEE in subtle ways and life will be good. On the other hand, a cocky, uncooperative, "why me" attitude can lead to problems, including colleagues sitting on promotion and tenure committees a few years later with bad memories and hard feelings regarding the NEE's first year or two.

K. Put class policies and grading standards down in writing and distribute to students in every class. The author has developed a class policy document that has evolved over nearly twenty years and spells out numerous issues and policies associated with his classes. He updates it every semester to address any new problems or issues. The document has guidelines for laboratory notebooks and reports, term papers, and design projects. It has recommendations for homework, studying, and test taking. It includes the university Academic Integrity Policy formally addressing student cheating. There are few problems that could arise between student and professor that are not addressed by the evolving document. The author requires that all students study it every semester and gives a brief quiz over it. Although occasionally the target of jokes and criticisms, the document has been successful in preventing problems, misunderstandings, and disagreements between student and instructor. Students know what's required and disciplinary issues have been rare.

L. Related to K. is the need for a NEE to get his "bluff" in with students early in his career and particular courses. Some will push the envelope hard and test the commitment of the NEE to his policies. Take a firm stand when challenged and pass a strong message that one means what one says and will back it up. One may have to make an example of offending students by public airing of offenses and invoking maximum penalties. Any exceptions to policy should be done so as to avoid giving students the impression that the NEE has been persuaded or forced into them, that is, "given-in". Any perceived wavering or capitulation will open the floodgates and one will be nickeled and dimed to death with misbehavior, tardiness, lateness, and

Proceedings of the 2003 American Society for Engineering Education Annual Conference \& Exposition Copyright (C 2003, American Society for Engineering Education 
negotiations. Nip it in the bud by, again, being "firm, fair, and consistent." Always maintain a certain line of separation and authority between oneself and students.

M. Plug into the student grapevine. Keep one's ears and eyes open and read student expressions, mannerisms, and actions. Remember that actions speak louder than words. Try to develop a close but always professional relationship with a few students and diplomatically solicit their honest, reprisal-free input regarding what students really feel about one's teaching.

N. Do not let students eat up all of one's time, either in class with inappropriate discussions or excessive requests of "Will you work Problem so-and-so?", or in one's office with similar chit chat or excessive requests for assistance. A NEE must manage time wisely and leave a significant amount for service, professional development, and research $[3,10,11]$ in order to be promoted and tenured. Many NEE get behind in getting research programs going the first year or two due to too much time committed to instruction and students. Yes, aim for excellence in teaching but not to the detriment of these other critical components. Again, balance and unambiguous policies are the keys. Insist that students have first tried to master a concept or homework problem on their own before requesting help, that they get to the point, and that they adhere to one's policies and office hours.

O. Become aware of new, often high-tech, ways for students to cheat, address them in one's written class policy, and do not tolerate them. Spell out how calculators can and cannot be used. Be aware of how students can access instructors' web sites and solutions manuals with a little hacking. Data and documents can be transferred nearly instantaneously all over the world with a click of the keyboard. Also be familiar with the old fashioned ways of cheating; they still exist. Apply the "Red Hot Stove Rule" to all instances of cheating, after first defining what is and isn't allowable, for instance, how much students can help each other with homework assignments.

$\mathrm{P}$. The flip side of $\mathrm{O}$. is balanced use of educational innovations and technologies by the NEE and students. The Internet and e-mail have opened up new opportunities for communication, scholarship, and learning if used ethically. Digital cameras and graphics programs work wonders in incorporation of images in documents and presentations. Spreadsheets and simulation packages, for example MATLAB and MATHCAD, have worked similar wonders for engineering calculations. NEE should strike balance between the time-tested ways of teaching such as chalk and chalkboard, and new technologies, such as slide presentations or projection of a computer monitor onto a screen. Computer-based courses and distance learning are also on the increase. Technical innovations have potential to be either valuable tools to aid in the learning process or distracting obsessions if too much emphasis and time are applied to them to the detriment of actual teaching and learning of course material. NEE should assess 
pros, cons, and likely ramifications of incorporating such methods in classes and, if the outlook is positive, should gradually work them into their pedagogy.

Q. Be sensitive to the significant time, financial, and even relationship sacrifices of an undergraduate and family. Although some students may have a college education handed to them on a silver platter, many go to significant lengths to obtain one, namely leaving family and friends, paying huge tuitions and fees, and keeping long hours, including nights, weekends, and holidays, studying for multiple classes. The life of an engineering undergraduate can be extremely demanding and stressful. Although never an excuse for sub-par performance, this should always be kept in mind by faculty. Aim for both effective and efficient use of time in education and a maximum rate-of-return in learning with respect to time, money, and energy invested by students. Avoid busy work assignments that are redundant, trivially plug-and-crank, or cumbersome in ways not directly related to learning course material. Students and faculty should plan, organize, streamline, and work smart as well as work hard. Design questions, assignments, tests, and class activities to maximize the learning experience relative to a reasonable degree of investment by professor and students. Don't assume that all students are going to graduate school or will end up with a career in research and development. Incorporate practical, real world components in the course.

R. Frequently assess student performance. The common model of a course grade being based solely on 2-3 test scores is far from optimum, although the author has also been guilty of this. Consider having more tests and generating more scores or points for students on graded homework, design projects [12], term papers, reports, computer assignments, etc., as long as contributing efficiently to the learning process. This will provide a more accurate and fair assessment, better justify final grades, minimize the odds of subsequent grievances, and give students a better chance of making up for a bombed test of missed assignment. Of course, one has to consider the impact on actual in-class and instructor time. Have a few tests in-class and a few more as take-home tests to avoid consuming too much time in-class. Although tests are usually graded by professors, homework and other assignments can be graded by capable graduate or even undergraduate students once the professor has provided them adequate guidelines.

S. Solicit and utilize all of the data available as feedback in teaching and class policy. Evaluations of course and instructor by students, emerging ABET 2000 accreditation data, student performance in subsequent classes, etc. all supplement input that one receives via word-of-mouth and observation. NEE may want to design their own vehicles for further assessment of their performance, for example, a separate, more detailed survey of student opinions, the last question on the final examination asking for strengths and weaknesses of the course and instructor (with firm guarantees of no reprisal for negative comments), or a rap session on the last day of class during which students are invited to speak their minds, again with a believable guarantee of instructor interest and no reprisals. 
Throughout this paper, terms of control systems theory have been used as analogies, for example, set point, steady state, equilibrium, steady state error, oscillation, settling time, damping, etc. A teacher is a control system. He/she controls the actuation and process by which students learn a predetermined body of knowledge of skills. As with a control system, this process can evolve and improve from the initial state toward an optimum steady state or equilibrium of standards, policies, and style in a smooth but prompt manner reminiscent of critical damping, a more gradual manner reminiscent of over damping with an excessively long time required to make needed changes, or a more dramatic and disconcerting, under damped, oscillatory manner. The former is the most desirable but not always easy to implement. It is hoped that this paper provided insight and perspective to assist the NEE in converging to an excellent teacher and an excellent professor in a broader sense.

Bibliography

1. Engelken, R; "Development, Survival, and Retention of Young Engineering Faculty: A Front Line View," 1986 ASEE/IEEE Frontiers in Education Conferences - Arlington, TX, Conference Proceedings, 354363 (1986).

2. $\quad$ Engelken, R; "Long Term Optimum Strategies for New Engineering Faculty: A View from a Decade Down the Road," 1997 Annual ASEE Conference - Milwaukee, WI, Conference Proceedings (on CD), Session 3675 (1997).

3. $\quad$ Engelken, R.; "Engineering Research at Predominately Undergraduate Institutions: Strategies and Pitfalls for the New Engineering Educators," 1999 Annual ASEE Conference - Charlotte, NC, Conference Proceedings (on CD), Session 0575 (1999).

4. Reis, R. M., Tomorrow's Professor: Preparing for Academic Careers in Science and Engineering, IEEE Press, 1997.

5. Menges, R. J. and Associates, Faculty in New Jobs: A Guides to Settling In, Becoming Established, and Building Institutional Support, Jossey-Bass Publishers, 1999.

6. Boice, R., The New Faculty Member, Jossey-Bass Publishers, 1992.

7. Gupta, M. S.-Editor, Teaching Engineering: A Beginner's Guide, IEEE Press in conjunction with ASEE, 1987.

8. R. Engelken, “Teaching Engineering Professionalism: Action's Speak Louder than Words or More Show than Blow Makes Jack a Well-Trained Engineer," 1987 IEEE/ASEE Frontiers in Education Conference Proceedings, 337 (1987).

9. R. Engelken, "Innovations in Undergraduate Education through NSF - ILI and NASA JOVE Program Sponsored Development of a Laboratory Course Sequence in Semiconductor Materials", IEEE

Proceedings of the 2003 American Society for Engineering Education Annual Conference \& Exposition

Copyright (C) 2003, American Society for Engineering Education 
Transactions on Education, 40, 259 (1997).

10. R. Engelken and H. McCloud, "Effective Management, Utilization, and Motivation of Undergraduate Research and Laboratory Assistants in Baccalaureate Engineering and Science Programs,” 1985 IEEE/ASEE Frontiers in Education Conference Proceedings, 390 (1985).

11. R. Engelken, "Integrating Undergraduate Instruction and Research: Thin Film Material Studies at Arkansas State University”, 1992 IEEE/ASEE Frontiers in Education Conference Proceedings, 534 (1992).

12. R. Engelken, "The Mini-Invention/Design Project: A Means to Foster Undergraduate Creativity, Intuition, and Communication Skills", 1987 IEEE/ASEE Frontiers in Education Conference Proceedings, 143 (1987).

13. R. Engelken, "The Role and Scope of Engineering Consulting in a Balanced and Integrated Career and Personal/Family Life of a New Engineering Educator," 2000 Annual ASEE Conference-St. Louis, MO, Conference Proceedings (on CD), Session 2793 (2000).

14. Matthew 7:12, The Holy Bible, New International Version (NIV).

\section{ROBERT ENGELKEN}

Dr. Robert D. Engelken was born on November 14, 1955 in Poplar Bluff, Missouri. He graduated from Walnut Ridge, Arkansas High School in 1974, obtained the B.S.-Physics from Arkansas State University in 1978, and the M.S.E.E. and Ph.D.-E.E. from the University of Missouri-Rolla in 1980 and 1983, respectively. He has been on the engineering faculty at Arkansas State University since 1982, is currently Director of Electrical, Computer, and Information Engineering, Professor of Electrical Engineering, and a Professional Engineer in the state of Arkansas. He is also a charter faculty member in ASU's relatively new multidisciplinary Ph.D. in Environmental Sciences program. He has been very active in research and development in the field of semiconductor thin films, particularly in the fields of electrodeposition and chemical precipitation deposition of such, with a major emphasis on undergraduate instruction and utilization of undergraduate research assistants in the field. He has had numerous research projects sponsored by agencies such as NASA, the National Science Foundation, the National Institutes of Health, the Environmental Protection Agency, and the Arkansas Science and Technology Authority. He also has played an active, senior role in the development of the electrical engineering program at ASU and has been active in the field of engineering education, including several presentations and papers at ASEE/IEEE Frontiers in Education and ASEE annual conferences. He has been active in ASEE, IEEE (including serving as Faculty Counselor to the ASU IEEE Student Branch), the Electrochemical Society, and the Arkansas Academy of Science. He is married and has two sons.

Proceedings of the 2003 American Society for Engineering Education Annual Conference \& Exposition

Copyright (C) 2003, American Society for Engineering Education 